\title{
Image Guided Endoscopic Sinus Surgery
}

\author{
Sang Chul Lim \\ Department of Otolaryngology-Head and Neck Surgery, Chonnam National University Medical School and \\ Chonnam National University Hwasun Hospital, Hwasun, Korea
}

\section{영상유도 부비동 내시경수술}

\author{
임 상 철 \\ 전남대학교 의과대학 이비인후과학교실
}

\author{
Received April 22, 2014 \\ Accepted October 3, 2014 \\ Address for correspondence \\ Sang Chul Lim, MD, PhD \\ Department of Otolaryngology- \\ Head and Neck Surgery, \\ Chonnam National University \\ Medical School and Hwasun \\ Hospital, 322 Seoyang-ro, \\ Hwasun 519-763, Korea \\ Tel +82-61-379-8190 \\ Fax +82-62-228-7743 \\ E-mail limsc@chonnam.ac.kr
}

The use of image guided endoscopic sinus surgery is becoming more popular. Image guided surgery (IGS) system (navigation system) allows realtime, intraoperative tracking of current location on preoperatively obtained image dataset. IGS is a valuable tool that may allow enable more radical surgical removal of disease. With help of image guidance, improved surgical outcome of the paranasal sinus and skull base diseases and decreased complication rate of endoscopic sinus surgery is anticipated. An IGS system consists of a computer workstation, imageprocessing software, a display monitor, a tracking system, and specialized instrumentation that can be tracked. There are two image guidance systems on the market: optical and electromagnetic tracking system. In this review, currently available technologies in the IGS are addressed. In addition, published articles regarding IGS are reviewed and discussed to investigate usefulness of IGS in treating diseases of the paranasal sinus and skull base. Contrary to previous articles, papers favoring impact of IGS have recently been published and endoscopic skull base surgery has gained its popularity over time and therefore, its use in the treatment of sinus disease can be justified. Although IGS is extremely useful for anatomic location in at-risk structures, it should be regarded as an adjuvant tool. First of all, accurate knowledge of anatomy and surgeon's experience is mandatory for effective control of diseases of the paranasal sinuses and skull base. Korean J Otorhinolaryngol-Head Neck Surg 2015;58(5):305-12

Key Words Complications · Endoscopy · Image guided surgery · Treatment outcome.

\section{서 론}

영상유도수술(image guided surgery, IGS)은 IGS 시스템 (또는 navigation system)을 이용하여 환자의 영상자료와 환 자의 실물을 일치시켜 실시간으로 환자의 구조물을 확인하 면서 수술하는 것을 말하며, computer aided surgery의 한 분 야라고 할 수 있다. 1970년대 CT가 도입되고 컴퓨터 공학기 술이 발전함에 따라 1980년대 초반부터 프레임을 사용하는 IGS(frame based stereotactic surgery)가 신경외과에서 시도되 었으며, 1987년 Allen 등이 프레임을 대체해서 fiducial marker 를 사용할 것을 제안한 이후 fiducial marker를 이용한 IGS가 시도되었다. ${ }^{1)}$ 비과영역의 IGS 시스템은 1980년 독일의 Klimek
을 주축으로 한 Aachen 그룹에 의해 처음으로 개발되었으며, ${ }^{2)}$ 1993년 212예의 부비동 수술에서 시도되어 종양, 과거 수술, 및 출혈로 인해 외과적 표지자가 불확실한 경우 IGS가 유용 하였으며 합병증 발생률을 $2 \%$ 정도 낮추었다고 보고하였다. ${ }^{3)}$ 미국에서는 1994년 Anon 등 ${ }^{4}$ 에 의해 70예의 부비동 내시경수 술 결과를 보고하였다. 1990년대 후반에 이르러 IGS 시스템의 발전으로 비과분야에 IGS가 적극적으로 시도되면서 여러 연구 들이 발표되었다. ${ }^{5-7)}$

\section{IGS 시스템의 구성}

IGS 시스템(navigation 시스템)은 워크스테이션 컴퓨터, 영 
상처리 소프트웨어, 디스플레이 모니터, 추적장치(광학 또는 자기장 추적장치), 위치를 추적할 수 있는 탐침 또는 수술 기 구로 구성된다.

\section{정합(Registration)}

$\mathrm{IGS}$ 시스템의 기능은 수술의사가 실시간으로 환자의 3차원 수술시야를 확보하고 환자에서 현재의 위치를 정확히 확인 하는 것이다(Fig. 1). IGS를 하기 위해서는 먼저 술전 영상을 얻고 수술시작 전에 술전 영상과 환자를 일치시키는 과정이 반드시 필요하다. 정합이란 환자의 영상자료와 실제 환자의 수술부위를 삼차원적으로 일치시키는 과정을 말하고 IGS 시 스템의 정확도에 관여하는 가장 중요한 인자로 알려져 있다. IGS 시스템에 사용되는 술전 영상에는 CT, MRI, PET, fMRI, SPECT 등이 사용될 수 있으나 CT가 가장 흔하게 쓰이며 영 상자료의 해상도가 높을수록 높은 정확도를 가질 수 있다.

영상-환자 정합방식(image to patient registration)은 크게 3가지로 나누어지는데 paired point registration(PPR), automatic registration, contour based registration(CBR)이 있다. ${ }^{89}$ $\mathrm{PPR}$ 이 기본적인 정합방식이며 fiducial marker를 사용하는 방법과 maker 없이 하는 방법으로 나눌 수 있다. ${ }^{10)}$ Marker based registration 중에서 가장 정확한 방법은 두개골에 고정 된 골스크류(bone screw)를 이용하는 bone anchored fiducial registration이다. 하지만 이 방법은 침습적인 방법이기 때문에 잘 사용되지 않는다. ${ }^{11,12)}$ Skin affixed fiducial registration은 수술 전에 환자의 두피에 여러 개의 fiducial marker를 테이 프로 붙이고 $\mathrm{CT}$ 를 찍은 다음 수술장에서 정합을 하는 방식 이다(Fig. 2). ${ }^{8}$ 이 방법은 정확하고 빠른 정합을 할 수 있지만, ${ }^{13}$ 조직의 부종이나 이동에 의해 fiducial marker가 움직여서 정 확도가 떨어지는 단점이 있다. 신경외과에서 주로 이용되는 방 식으로, 머리를 핀으로 고정해야 하기 때문에 일반적인 부비 동 내시경수술에는 잘 사용되지 않는다. Anatomic fiducial registration(또는 anatomical landmark registration)은 fiducial marker를 사용하지 않고 환자의 머리 또는 얼굴의 해 부학적 구조물(예를 들면, nasion, rhinion, lateral canthus 등) 을 직접 선택해서 정합하는 방법으로, 간단한 방법이지만 정확 도가 떨어져서 잘 사용되지 않는다.") Automatic registration 은 fiducial marker를 plastic head frame에 포함시킨 것으 로, head frame을 쓴 환자가 술전 CT를 찍고 난 후 수술장에 서 특별한 정합과정 없이 자동적으로 정합이 가능케 하는 방 법이다. 정합이 빠르고 쉽다는 장점은 있지만 head frame의 위 치가 변하거나 수술방법에 맞게 fiducial marker의 배치를 바 꿀 수 없는 단점이 있다. ${ }^{899}$ CBR은 surface matching technique 이라고도 하는데 술전 $\mathrm{CT}$ 를 이용하여 삼차원 얼굴영상을 만든 다음 수술장에서 probe나 laser를 이용해 만든 얼굴의 윤곽과 정합하는 방법이다(Fig. 3). 이 방식은 다른 방식에 비

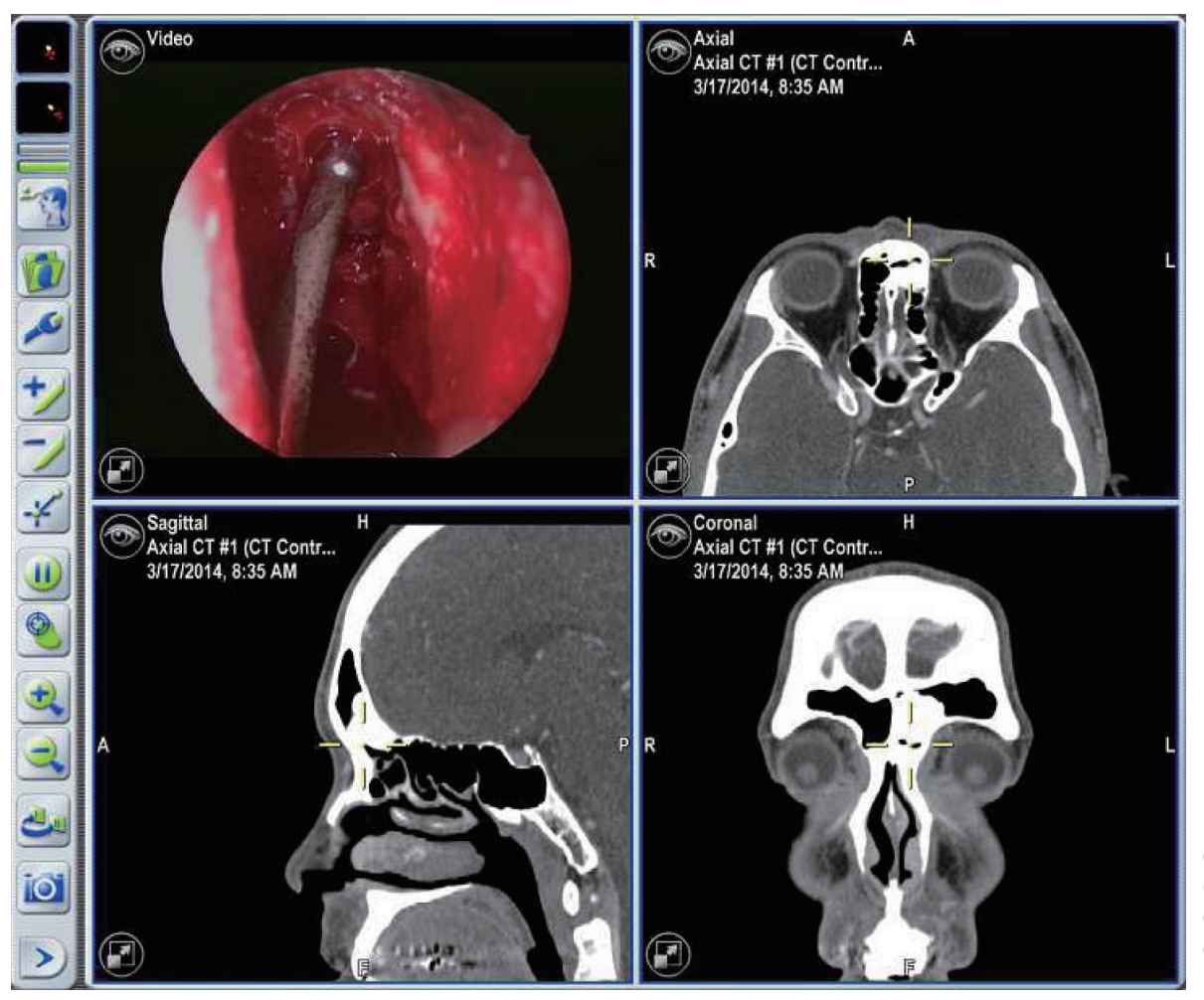

Fig. 1. Intraoperative snap shot during endoscopic removal of a frontal osteoma: the upper right panel is the endoscopic view and the position of the curved suction tip is projected on the axial, coronal, and sagittal CT images. 


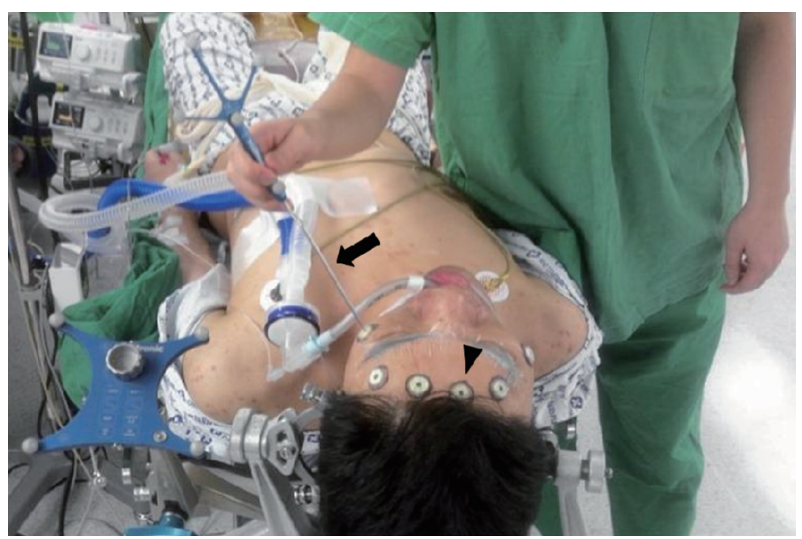

Fig. 2. Paired point registration (StealthStation S7, Medtronics): probe (arrow), skin affixed fiducial marker (arrowhead).

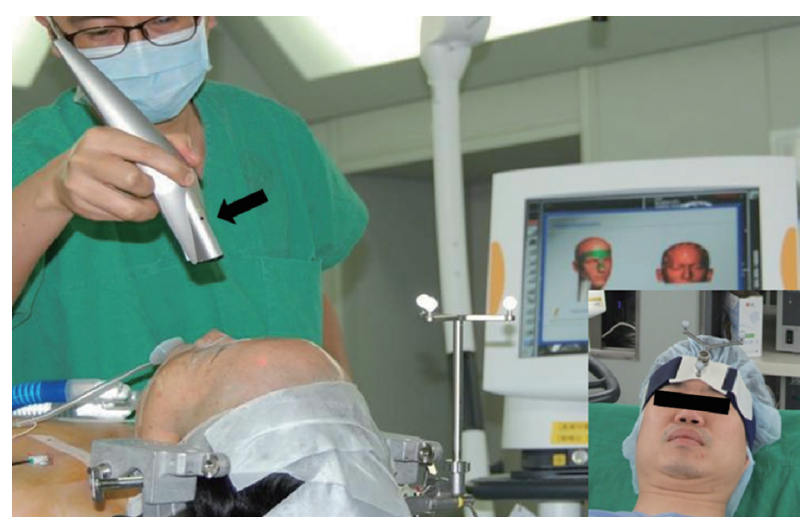

Fig. 3. Contour based registration (Kolibri, BrainLab): laser surface scanner (arrow), headset used in endoscopic sinus surgery (right bottom).

해 고가라는 단점이 있지만 headset이 필요 없고 간편하고 효 과적이어서 부비동 내시경수술시에 널리 사용된다. 이 방식은 머리의 후방 쪽으로 가면 정확도가 감소할 수 있다. ${ }^{912)}$ 이러한 경우에는 hybrid registration technique을 사용할 수 있는데 $\mathrm{PPR}$ 과 $\mathrm{CBR}$ 을 동시에 하기 때문에 단독보다 더 정확하다고 한다. ${ }^{14)}$

정합 오류(registration error)에는 fiducial localization error (FLE), fiducial registration error(FRE), target registration error(TRE)가 있다. ${ }^{8}$ FLE는 술전 영상의 fiducial marker의 위치와 환자에 부착된 fiducial marker의 실제 위치와의 거리 차이이고, FRE는 정합 후 환자의 fiducial marker가 측정된 위치와 영상에서 측정된 위치의 거리 차이이며 각 fiducial의 정합 오류라고 말할 수 있다. TRE는 정합 후 영상의 수술목표 부위의 위치와 환자에서의 수술목표부위 위치와의 거리 차이 이며, 이 수치가 실제 수술시 IGS 시스템의 정확도를 의미한다. 과거에는 정합과정이 복잡해서 시술자의 경험이 필요하였지만 요즘에는 정합과정이 단순화되어 있어 비교적 간단하게 정합 을 마칠 수 있다. 그럼에도 불구하고 IGS 시스템을 장착하고
정합하는 데에는 추가시간이 소요된다. 많은 연구에서 약 15 분 정도의 준비시간이 필요하다고 보고되고 있지만, ${ }^{15)}$ 기계적인 이상이 발생하면 더 많은 시간이 소요될 수 있다.

\section{추적장치(Tracking Device)}

병변, 해부학적 구조물 또는 수술기구의 위치를 확인하기 위해서는 추적장치가 필요하다. 추적장치의 종류에는 여러 가지 방식이 있으나 ${ }^{10)}$ 실제 임상에서는 광학 추적장치(optical tracking device)와 자기장 추적장치(electromagnetic tracking device)가 가장 널리 사용된다. 광학 추적장치는 적외선(infrared)을 이용하는 방식으로 optical marker의 방식에 따라 능 동형과 수동형으로 나눈다. 능동형은 기구나 head frame에 부착된 light-emitting diode에서 방출하는 적외선을 카메 라에서 추적하는 방식이고, 수동형은 적외선 카메라에서 방 출되는 적외선을 optic marker에서 반사시켜 추적하는 방식 이다. 광학 추적장치의 장점은 모든 기구를 수술 중에 calibration해서 IGS 시스템에 사용할 수 있고 충분한 정확도를 얻 을 수 있다는 것이다. ${ }^{9)}$ 그러나 광학 추적장치의 단점은 카메 라와 optical marker의 사이를 방해물이 가리면 위치추적이 불 가능하다는 것이다. 자기장 추적장치는 환자 옆에 위치한 자기 장 전송자(electrical transmitter)에서 발생한 자기장을 수술기 구에 포함된 수신기가 자기장 범위 내의 위치를 감지한다. 이 방식은 상대적으로 저렴하며 광학 추적장치와 달리 자기장 전 송자와 수신기 사이에 물체가 놓여도 작동되는 장점이 있다. 특별히 고안된 기구만이 IGS 시스템에 사용될 수 있으며, 환자 주변에 금속이 있으면 자기장 신호가 방해 받아 정확도가 떨 어지는 단점이 있다. 또 심장 박동기나 인공 와우 환자는 주의 해서 사용하여야 한다. ${ }^{16)}$

\section{정확도(Accuracy)}

IGS 시스템의 정확도는 부비동 내시경수술의 경우 $2 \mathrm{~mm}$ 이 하이면 충분하다고 하며, 두개저 수술을 시행할 경우에는 1 $\mathrm{mm}$ 이하의 정확도가 요구되기도 한다. IGS 시스템은 $1 \mathrm{~mm}$ 이하의 정확도를 보고하지만 그것은 이상적인 조건에서의 결 과이고 실제 임상에서는 $1.5 \sim 2.0 \mathrm{~mm}$ 의 정확도가 보고되었 다. ${ }^{17)}$ 정확도의 감소에는 다양한 이유가 있는데, IGS 시스템 의 기술, CT 슬라이스 간격, 영상재건 알고리즘, 스캐너 기술, 방사선 조사 용량, 표면 재건시 배경 노이즈 등이 있다. ${ }^{18)}$

IGS 시스템이 개발되던 초기에는 자기장 추적장치가 광학 추적장치에 비해 정확도가 낮았다고 알려졌으나, 현재는 두 방식 모두 정확도를 $2 \mathrm{~mm}$ 이하로 낮출 수 있기 때문에 임상 
적인 사용에서는 큰 차이가 없다고 한다. $\mathrm{Kral}$ 등 $^{19}$ 의 실험연 구에서 부비동과 전두동 두개저 수술시 광학 추적장치와 자 기장 추적장치의 정확도를 비교하였는데, 두 가지 추적장치 모두 $1 \mathrm{~mm}$ 이하의 TRE를 보였으며 광학 추적장치가 자기 장 추적장치보다 더 정확하다고 보고하였다. 실제 임상에서 는 자기장 추적장치도 충분한 정확도를 가질 것으로 판단되 고 추적장치의 방식보다는 오히려 정합과정에서의 오류를 최 소화하는 데 주력해야 한다. 정합방식도 정확도에 영향을 주 는데 PPR의 경우 fiducial 위치(fiducial point selection), fiducial 수(fiducial point number), fiducial 배치(fiducial configuration)를 고려해야 한다. ${ }^{8)}$ Fiducial의 위치가 적절치 못하 면 정확도가 떨어지며, 적어도 3 개 이상의 fiducial이 있어야 삼차원 영상을 구현할 수 있으며 이론적으로는 fiducial 개수 가 많을수록 좋다. ${ }^{8,20}$ 그러나 좁은 면적에 fiducial 개수가 너 무 많으면 오히려 정확도를 낮출 수 있으며 6개 이상 사용하 더라도 크게 유리하지는 않다고 한다. ${ }^{10)}$ Fiducial을 배치할 때 수술 부위의 주변에 대칭적으로 삼차원으로 분포시키고 관 심부위가 fiducial 배치의 중심부(centroid)에 위치하도록 한 다. ${ }^{8,20)}$ 근래에는 부비동 내시경수술시 사용되는 IGS 시스템의 경우, fiducial이 내장된 headset이나 probe 또는 laser를 사용 하여 $\mathrm{CBR}$ 을 하기 때문에 fiducial 위치나 개수에 의한 오류 가 능성은 낮다. 그러나 fiducial이 내장된 headset을 사용할 경우 실제 상황에서 정확도가 떨어질 수 있는데 이는 headset의 위 치 변화 등 다른 인자를 고려해야 한다. ${ }^{21)} \mathrm{Hardy}$ 등 ${ }^{22)}$ 은 광학 추적장치를 이용해서 3가지 방식(fiducial marker registration, surface matching registration, anatomical landmark registration)의 정합오류를 비교한 연구에서 fiducial marker registration은 $0.48 \pm 0.21 \mathrm{~mm}$, surface matching registration $1.05 \pm 0.06 \mathrm{~mm}$, anatomical landmark registration $3.1 \pm 0.25$ $\mathrm{mm}$ 의 정합오류를 보고하였고, 세 가지 방식 중에서 fiducial marker registration이 가장 정확하였고 정합시간은 surface matching registration이 1 분 1 초 \pm 5 초로 가장 빨랐다고 보고 하였다. 또 영상자료는 주로 CT를 사용하는데 CT 영상은 고 해상도와 최소 간격의 CT 영상을 얻어야 하며, CT가 MRI 등 타 영상자료에 비해 정확도에서 더 우수하다.

IGS는 수술 전 영상을 이용하기 때문에 수술시 연부조직의 움직임이 IGS 시스템의 정확도를 떨어뜨린다. 신경외과수술 의 경우 개두술을 하면 뇌의 이동이 발생하는 등 수술적 처치 에 의해 구조적인 변화가 오기 때문에 정확한 위치확인이 어려 울 수가 있다. 반면, 부비동 내시경수술의 경우, 수술의 경계 부위와 중요표지구조물이 골조직이어서 뇌수술과 달리 조직 의 움직임이 없어 IGS 시스템의 사용에 있어 이상적인 조건을 갖추고 있다. 환자의 병변이나 해부학적 구조물은 수술 도중
항상 변화할 수 있기 때문에 IGS 시스템의 정확도가 항상 일 정한 것은 아니라는 것을 명심해야 한다. Metson 등근 부비 동 및 두개저 수술 시작시 $2 \mathrm{~mm}$ 이하의 정확도를 보였고 수 술이 끝날 때는 수술에 의한 구조물의 이동 때문에 정확도가 평균 $0.89 \mathrm{~mm}$ 정도 더 나빠진다고 보고하였다. 병변의 위치나 수술 도중 머리의 움직임, 기구의 calibration 소실 등으로 정확 도가 변화할 수 있기 때문에 주의를 요하며, fiducial marker 들의 중심에서 거리가 멀어지거나 $\mathrm{CBR}$ 의 경우에 머리의 후방 으로 갈수록 정확도가 감소하기 때문에 위치추적이 부정확해 진다. ${ }^{20)}$ 또 정합 후 정확도를 확인할 때 코끝, 인중 등에서 시 행하는 경우가 많은데 이 부위의 정확도가 반드시 수술자가 관심을 갖는 깊은 부위의 정확도를 반영하지 않는다는 것을 알고 있어야 한다. ${ }^{20)}$ 따라서 관심부위에 가까이 접근하면 주 변의 알고 있는 해부학적 구조물을 확인해서 정확도 오류가 있는지 확인하는 것이 중요하다.

현재 국내에서 시판되고 있는 항법장치(navigation system) 는 Table 1에 기술되어 있다.

\section{임상 적용}

2002년 미국이비인후과학회에서는 영상유도수술의 적응증 을 부비동 재수술, 발생과 수술, 또는 외상에 의한 부비동 해 부구조의 변화, 광범위한 비부비강 비용, 전두동과 후사골동 및, 접형동의 병변, 뇌척수액 비루 또는 두개저의 결손병변, 양성 또는 악성 비부비강 종양으로 정하였으며, ${ }^{23)}$ 최근 2013 년 Dalgorf 등 ${ }^{24}$ 의 연구에서는 오스트레일리아의 IGS 적응증 을 보고하였다(Table 2). 국내에서는 2012년 보건복지부고시 에 따라 부비동 재수술, 발육, 외상, 이전 수술에 기이한 해부 학적 왜곡, 광범위한 비강내 용종, 전두동, 사골동 후부 또는 접형골동 관련 병리의 부비동 질환인 경우에 법정비급여로 인정되었다.

국내의 문헌 검색에 따르면 영상유도 부비동 내시경수술은

Table 1. Commercially available navigation systems in current domestic market

\begin{tabular}{llll}
\hline Company & \multicolumn{1}{c}{ System } & Tracking system & Registration \\
\hline Xomed & Fusion & Electromagnetic & PPR \\
& & CBR with touch \\
& StealthStation & Optical, passive & PPR \\
BrainLab & Kolibri & Optical, passive & PPR \\
& & & CBR with laser \\
Fiagon & Fiagon & Electromagnetic & CBR with touch \\
Stryker & Navi3 & Optical, active & PPR \\
& & & Autoregistration \\
& & & mask
\end{tabular}

PPR: paired point registration, CBR: contour based registration 
Table 2. Indications for image guided endoscopic surgery

\begin{tabular}{|c|c|}
\hline $\begin{array}{l}\text { American Academy of Otolaryngology-Head and } \\
\text { Neck Surgery Indications }{ }^{23} \text {. }\end{array}$ & Australian expert panel recommandations ${ }^{24)}$ \\
\hline 1. Revision sinus surgery & 1. Recommended \\
\hline $\begin{array}{l}\text { 2. Distorted sinus anatomy of development, postoperative, or } \\
\text { traumatic origin }\end{array}$ & $\begin{array}{l}\text { a. Stereotactic directed external localization of frontal } \\
\text { pathology (not mini-trephination) }\end{array}$ \\
\hline 3. Extensive sinonasal polyposis & b. Endoscopic frontal sinus surgery in the setting of prior \\
\hline 4. Pathology involving the frontal, posterior ethmoid, and & external frontal or external ethmoid surgery \\
\hline sphenoid sinuses & c. Endoscopic sinus surgery in the setting of prior \\
\hline 5. Disease abutting the skull base, orbit, optic nerve, or & reconstruction of the ventral skull base \\
\hline carotid artery & d. Pathology beyond the anatomical limits of the paranasal \\
\hline $\begin{array}{l}\text { 6. CSF rhinorrhea or conditions in which there is a skull } \\
\text { base defect }\end{array}$ & $\begin{array}{l}\text { sinuses (excluding lacrimal surgery and biopsy of exophytic } \\
\text { tumor) }\end{array}$ \\
\hline \multirow[t]{17}{*}{ 7. Benign and malignant sinonasal neoplasms } & $\begin{array}{l}\text { e. Benign and malignant neoplasia involving the ventral skull } \\
\text { base (not diagnostic) }\end{array}$ \\
\hline & f. Draf 3 procedure \\
\hline & 2. Optional (important) \\
\hline & $\begin{array}{l}\text { a. Extensive nasal polyposis (involving all sinuses either } \\
\text { unilateral or bilateral) in which all sinuses are addressed }\end{array}$ \\
\hline & b. Revision frontal sinus surgery \\
\hline & $\begin{array}{l}\text { c. Benign and malignant neoplasia of the paranasal sinuses } \\
\text { not involving the ventral skull base (not diagnostic) }\end{array}$ \\
\hline & 3. Optional (helpful) \\
\hline & a. Revision sinus surgery \\
\hline & $\begin{array}{l}\text { b. Distorted sinus anatomy of developmental, postoperative, } \\
\text { or traumatic origin }\end{array}$ \\
\hline & c. Congenital abnormality \\
\hline & d. Training/education \\
\hline & e. Specific \\
\hline & i. Pediatrics \\
\hline & ii. Cystic fibrosis \\
\hline & iii. Sphenoid surgery \\
\hline & iv. Frontal sinus surgery \\
\hline & v. Mucoceles \\
\hline
\end{tabular}

Ahn과 Chung ${ }^{25)}$ 에 의해 만성 부비동염 환자에서 2000년 처 음 보고되었으며, 2006년 $\mathrm{Kim}$ 과 $\mathrm{Lim}^{26)}$ 의 연구에서 진행된 부비동 및 두개저 질환의 내시경 진단과 치료 결과를 보고하 였다. 하지만 두 연구에서 사용되었던 IGS 시스템은 요즘의 $\mathrm{CBR}$ 방식과 다른 fiducial 방식이어서 머리를 핀으로 고정해 야 했기 때문에 부비동 내시경수술을 받는 환자에게는 불편 이 따랐던 방식이었다. 2000년대 후반에도 고가의 IGS 시스 템 사용에 대해서 이비인후과의 의료수가를 인정하지 않는 상 황 속에서 소수의 병원에서만 임상에서 사용되어왔다. 2012년 부터 영상유도내시경수술이 법정비급여로 인정받으면서 IGS 시스템을 사용하여 부비동 수술을 하는 병원이 많이 늘고 있 지만 그 실태에 대해서는 아직 조사된바 없다. 미국에서는 비 과학회 회원을 대상으로 IGS 시스템의 사용에 대한 우편설문 조사가 두 차례 시행되었는데 2005년 조사에 비해 2010년의 설문조사에서 IGS 시스템의 사용빈도가 현저하게 증가하였
으며 전사골동 일차수술, 전사골동 재수술, 사골동 일차수술, endoscopic modified Lothrop procedure, 뇌척수액 누출 수술, 전두개저 종양제거, 안와 감압술, 시신경 감압술에서 통 계적으로 의미있게 과거에 비해 사용빈도가 증가하였다고 한 다. ${ }^{27,28)}$ 특히 전사골동 일차수술의 경우에도 2005년 절대 적 응증 $0.6 \%$, 상대 적응증 $8.8 \%$ 에서 2010년 $1.2 \%, 14.5 \%$ 로 증 가되었으며, 전후사골동 일차수술의 경우는 2005년 절대 적 응증과 상대 적응증 $6.2 \%, 23.7 \%$ 에서 2010년 6.6\%,34\%로 사 용빈도가 증가됨을 보고하였다. 그리고 재발된 병변이나 진행 된 병변의 경우가 IGS 시스템을 사용하는 주된 적응증이었다 고 한다. ${ }^{28)}$ 하지만 IGS 시스템이 치료 성적이나 합병증의 발생 에 영향을 주는지는 아직 불명확하다. 그 이유는 IGS 시스템 의 효율성을 검증하기 위해 IGS 시스템이 필요한 환자를 대상 으로 무작위연구를 시행할 수는 없기 때문이다, 따라서 영상유 도 부비동 내시경수술(image guided endoscopic sinus sur- 
gery)의 효과에 대한 연구들은 대부분 후향적인 연구이고 전 향적인 연구가 많지 않아서 연구의 근거수준이 낮은 실정이다.

Tabaee 등 29 은 239명의 부비동 내시경수술을 시행 받은 환 자를 대상으로 IGS 시스템을 사용한 군과 사용하지 않은 군 간에 합병증 발생의 차이는 없었다고 보고하였다. 2008년 Tschopp과 Thomaser ${ }^{30}$ 가 시행한 123 명의 부비동 내시경수 술 환자를 대상으로 한 전향적 연구에 따르면 IGS 시스템을 사용하지 않는 군에서 합병증이 더 많이 발생하는 경향이 있 었지만 통계적 의의는 없었으며 증상의 호전은 두 군 간에 차 이가 없었다고 보고하였다. Mueller와 Caversaccio ${ }^{311}$ 는 276명 의 부비동염 환자에서 IGS가 합병증이나 재수술에 대해 영향 을 주지 않았다고 보고하였다. Ramakrishnan 등 ${ }^{22}$ 의 62823 명을 대상으로 한 후향적 다기관연구(2012)에서 뇌척수액비 루나 출혈 같은 합병증은 두 군 간에 차이가 없었으나 안와 손 상은 오히려 IGS 시스템 사용 군에 더 많았다고 $(p<0.005)$ 보 고하였다. Krings 등 33)의 후향적 연구에 따르면 부비동 내시경 수술을 받은 78944명의 합병증 발생을 조사하였는데, 중대 합병증 발생률은 $0.36 \%$ 였으며 IGS 시스템의 사용시 두개저 합 병증은 낮았지만 오히려 안와 합병증의 위험도를 높인다고 보고하였다. 이러한 역설적인 결과는 IGS 시스템은 주로 수 술하기 어려운 증례에서 사용되는 것과 항법 장치를 과신해서 안전하다고 착각할 수 있기 때문이라고 설명하고 있다. ${ }^{33)}$ 이러 하듯 과거의 여러 연구에서는 IGS 시스템의 사용이 수술합병 증의 감소나 치료결과의 향상 효과를 보이지 않았다. 하지만 이러한 한정된 연구결과를 가지고 IGS 시스템이 부비동염의 내시경수술에 필요없다고 단정할 수는 없는 것이다.

반면에 영상유도 부비동 내시경수술이 기존의 부비동 내시 경수술보다 효과적이라는 보고도 있다. Fried 등하)이 160명 의 $\mathrm{ESS}$ 환자를 대상으로 한 후향적 연구에서 IGS을 시행하 지 않은 군보다 IGS시행 군에서 중대 합병증의 발생이 적었다 고 보고하였다. Thong 등 ${ }^{35)}$ 의 전향적 연구에 따르면 image guided ESS를 받은 146명의 환자에서 1년 후 97\%에서 증상 의 호전과 내시경소견도 $85 \%$ 이상의 호전을 보였으며 합병증 은 없었다고 하였다. 최근 Dalgorf 등 ${ }^{24}$ 이 시행한 메타연구에 서도 IGS 미사용 군에서 주요합병증이 더 많이 발생하였으며 주요합병증과 단순합병증을 포함한 전체 합병증이 더 높았 지만, 두 군 간의 치료성적은 통계적 차이가 없었다고 보고하 였다. 저자들은 이 연구의 제한점으로서 두 군 간 질환의 정도 차이가 있을 수 있거나 병변이 심할수록 IGS를 사용하는 분할 오류가 생길 수 있다고 하였다. 이 연구는 만성 부비동염뿐만 아니라 두개저 질환도 일부 포함되어 있는 단점을 가지고 있 지만, 과거의 연구결과들과 달리 영상유도 부비동 내시경수 술이 기존의 부비동 내시경수술에 비해 수술 합병증을 의미있
게 줄인다는 근거를 제시하고 있다. ${ }^{24)}$

\section{소아의 IGS}

소아 부비동수술에 있어서 영상유도수술에 대한 연구는 많 지 않다. ${ }^{36,37)}$ Benoit 등 ${ }^{36}$ 이 시행한 최근의 연구에서 부비동 및 두개저 수술을 시행 받은 33예의 소아환자에서 합병증이 없었 고 의사만족도, 정확도, 사용횟수 등이 시간이 갈수록 더 증 가하였다고 보고하였다. 하지만 소아의 부비동 내시경수술에 서는 대부분의 경우 최소한의 수술을 시행하기 때문에 합병 증의 발생이 매우 낮아서 IGS가 실제로 도움이 되는 것인지는 아직 불확실하다. 일반적인 소아의 단순 부비동수술에서는 IGS가 필요치 않다고 생각되며 성인과 동일한 적응증을 갖는 경우에만 수술대상으로 하는 것이 바람직하다.

\section{최근의 연구}

Wise 등 ${ }^{38)}$ 이 시행한 실험연구에서 내시경 단독, 내시경과 술 전 CT, 내시경과 술전 CT-IGS, 내시경과 술중 CT-IGS 중에 서 술중 CT-IGS가 위치를 확인하는 데 가장 좋았다고 하였 으며 경험이 부족한 술자에게 교육적 효과가 있다고 보고하 였다. Jackman 등 ${ }^{39}$ 은 술중 CT를 이용한 IGS를 시행하여 $30 \%$ 의 환자에서 추가적인 사골동 수술을 시행할 수 있었다 고 보고하였다. 또 술중 cone beam CT를 이용한 IGS가 실제 환자나 실험연구에서 시행되고 있으며, ${ }^{40-42)}$ 이런 기법은 술전 $\mathrm{CT}$ 를 이용한 것과 달리 수술 당시의 상태를 실시간으로 확인 할 수 있다는 장점이 있다. Conley 등이은 부비동 및 두개저 질환 환자에서 $\mathrm{MDCT}$ 또는 cone beam CT를 이용한 IGS를 시행하고 술중 $\mathrm{CT}$ 가 환자의 $75 \%$ 에서 수술판단에 도움을 주 었다고 보고하였다. 술중 CT를 이용한 IGS는 사골동 수술 뿐만 아니라 전두동 수술에도 유용하지만 ${ }^{41)}$ 수술시 출혈이 정 상 봉소에 들어갈 경우 병변으로 착각할 수 있다는 단점이 있 다. IGS의 기술은 더욱 발전하여 image-enhance endoscopy 등 증강현실 기법이 현재 연구중이며 향후 임상에서 사용될 것이 기대된다. ${ }^{42-44}$

저자의 경험으로 보면 IGS가 단순 부비동염의 치료성적이 나 합병증 예방에 도움을 주는 것인지에 대해서는 아직 결론 지을 수는 없지만 IGS를 시작한 다음부터는 과거에는 수술 하기 어려웠던 부비동 및 두개저 복잡 병변의 수술을 더 쉽게 할 수 있게 되었다. 또 IGS 경험이 많아질수록 IGS를 하지 않 는 경우에 심리적으로 다소 불편감을 느끼는데 이는 수술의 사와 수술장비의 이중점검효과가 소실되기 때문이라고 판단 된다. IGS는 수술하기 어려운 병변을 해부학적 구조물을 실 
시간으로 추적함으로서 수술의사에게 자신감을 주고 수술영 역을 넓힐 수 있다는 것은 분명하다. IGS 시스템은 수술에 도 움을 주는 중요한 장비임에 분명하지만 정확도의 오류를 고 려할 때 절대적인 장치는 아니며 맹신하여서도 안된다. 가장 중요한 것은 수술자가 풍부한 경험과 해당부위의 정확한 해부 학적 지식을 갖추는 것이다.

\section{REFERENCES}

1) Peters TM. Image-guidance for surgical procedures. Phys Med Biol 2006;51(14):R505-40.

2) Klimek L, Mösges R, Schlöndorff G, Mann W. Development of computer-aided surgery for otorhinolaryngology. Comput Aided Surg 1998;3(4):194-201.

3) Mosges R, Klimek L. Computer-assisted surgery of the paranasal sinuses. J Otolaryngol 1993;22(2):69-71.

4) Anon JB, Lipman SP, Oppenheim D, Halt RA. Computer-assisted endoscopic sinus surgery. Laryngoscope 1994;104(7):901-5.

5) Fried MP, Kleefield J, Gopal H, Reardon E, Ho BT, Kuhn FA. Imageguided endoscopic surgery: results of accuracy and performance in a multicenter clinical study using an electromagnetic tracking system. Laryngoscope 1997;107(5):594-601.

6) Metson RB, Cosenza MJ, Cunningham MJ, Randolph GW. Physician experience with an optical image guidance system for sinus surgery. Laryngoscope 2000;110(6):972-6.

7) Metson R, Cosenza M, Gliklich RE, Montgomery WW. The role of image-guidance systems for head and neck surgery. Arch Otolaryngol Head Neck Surg 1999;125(10):1100-4.

8) Knott PD, Batra PS, Citardi MJ. Computer aided surgery: concepts and applications in rhinology. Otolaryngol Clin North Am 2006;39(3): 503-22, ix.

9) Kingdom TT, Orlandi RR. Image-guided surgery of the sinuses: current technology and applications. Otolaryngol Clin North Am 2004;37(2):381-400.

10) Eggers G, Mühling J, Marmulla R. Image-to-patient registration techniques in head surgery. Int J Oral Maxillofac Surg 2006;35(12): 1081-95.

11) Holloway KL, Gaede SE, Starr PA, Rosenow JM, Ramakrishnan V, Henderson JM. Frameless stereotaxy using bone fiducial markers for deep brain stimulation. J Neurosurg 2005;103(3):404-13.

12) Strong EB, Rafii A, Holhweg-Majert B, Fuller SC, Metzger MC. Comparison of 3 optical navigation systems for computer-aided maxillofacial surgery. Arch Otolaryngol Head Neck Surg 2008;134 (10):1080-4.

13) Knott PD, Batra PS, Butler RS, Citardi MJ. Contour and paired-point registration in a model for image-guided surgery. Laryngoscope 2006;116(10):1877-81.

14) Maurer CR, Aboutanos GB, Dawant BM, Margolin RA, Maciunas RJ, Fitzpatrick JM. Registration of CT and MR brain images using a combination of points and surfaces medical imaging. Proc SPIE 1995;2434:109-23.

15) Hosemann W, Draf C. Danger points, complications and medico-legal aspects in endoscopic sinus surgery. GMS Curr Top Otorhinolaryngol Head Neck Surg 2013;12:Doc06.

16) Widmann G. Image-guided surgery and medical robotics in the cranial area. Biomed Imaging Interv J 2007;3(1):e11.

17) Citardi MJ, Batra PS. Intraoperative surgical navigation for endoscopic sinus surgery: rationale and indications. Curr Opin Otolaryngol Head Neck Surg 2007;15(1):23-7.

18) Dubach P, Eichenberger A, Caversaccio M. Radiation dose reduction in computer assisted navigation for functional endoscopic sinus surgery--cadaver head experiments and clinical implementation.
Rhinology 2010;48(3):339-43.

19) Kral F, Puschban EJ, Riechelmann H, Pedross F, Freysinger W. Optical and electromagnetic tracking for navigated surgery of the sinuses and frontal skull base. Rhinology 2011;49(3):364-8.

20) Citardi MJ, Batra PS. Image-guided sinus surgery: current concepts and technology. Otolaryngol Clin North Am 2005;38(3):439-52, vi.

21) Knott PD, Maurer CR, Gallivan R, Roh HJ, Citardi MJ. The impact of fiducial distribution on headset-based registration in image-guided sinus surgery. Otolaryngol Head Neck Surg 2004;131(5):666-72.

22) Hardy SM, Melroy C, White DR, Dubin M, Senior B. A comparison of computer-aided surgery registration methods for endoscopic sinus surgery. Am J Rhinol 2006;20(1):48-52.

23) American Academy of Otolaryngology-Head and Neck Surgery. [Accessed on 2014 March 20]. Available from: URL: http://www. entnet.org/Practice/policyIntraOperativeSurgery.cfm.

24) Dalgorf DM, Sacks R, Wormald PJ, Naidoo Y, Panizza B, Uren B, et al. Image-guided surgery influences perioperative morbidity from endoscopic sinus surgery: a systematic review and meta-analysis. Otolaryngol Head Neck Surg 2013;149(1):17-29.

25) Ahn CM, Chung DH. 3 cases of computer aided endoscopic sinus surgery. Korean J Otolaryngol-Head Neck Surg 2000;43(2):225-8.

26) Kim K, Lim SC. Image-guided surgery in the paranasal sinus and skull base lesion. Korean J Otolaryngol-Head Neck Surg 2006;49(11): 1082-6.

27) Orlandi RR, Petersen E. Image guidance: a survey of attitudes and use. Am J Rhinol 2006;20(4):406-11.

28) Justice JM, Orlandi RR. An update on attitudes and use of imageguided surgery. Int Forum Allergy Rhinol 2012;2(2):155-9.

29) Tabaee A, Hsu AK, Shrime MG, Rickert S, Close LG. Quality of life and complications following image-guided endoscopic sinus surgery. Otolaryngol Head Neck Surg 2006;135(1):76-80.

30) Tschopp KP, Thomaser EG. Outcome of functional endonasal sinus surgery with and without CT-navigation. Rhinology 2008;46(2):11620.

31) Mueller SA, Caversaccio M. Outcome of computer-assisted surgery in patients with chronic rhinosinusitis. J Laryngol Otol 2010;124(5): $500-4$.

32) Ramakrishnan VR, Orlandi RR, Citardi MJ, Smith TL, Fried MP, Kingdom TT. The use of image-guided surgery in endoscopic sinus surgery: an evidence-based review with recommendations. Int Forum Allergy Rhinol 2013;3(3):236-41.

33) Krings JG, Kallogjeri D, Wineland A, Nepple KG, Piccirillo JF, Getz AE. Complications of primary and revision functional endoscopic sinus surgery for chronic rhinosinusitis. Laryngoscope 2014;124(4): $838-45$.

34) Fried MP, Parikh SR, Sadoughi B. Image-guidance for endoscopic sinus surgery. Laryngoscope 2008;118(7):1287-92.

35) Thong JF, Lee J, Yeak S, Siow JK. Use of image guidance in endoscopic sinus surgery. Clin Otolaryngol 2007;32(6):500.

36) Benoit MM, Silvera VM, Nichollas R, Jones D, McGill T, Rahbar R. Image guidance systems for minimally invasive sinus and skull base surgery in children. Int J Pediatr Otorhinolaryngol 2009;73(10): 1452-7.

37) Parikh SR, Cuellar H, Sadoughi B, Aroniadis O, Fried MP. Indications for image-guidance in pediatric sinonasal surgery. Int J Pediatr Otorhinolaryngol 2009;73(3):351-6.

38) Wise SK, Harvey RJ, Goddard JC, Sheahan PO, Schlosser RJ. Combined image guidance and intraoperative computed tomography in facilitating endoscopic orientation within and around the paranasal sinuses. Am J Rhinol 2008;22(6):635-41.

39) Jackman AH, Palmer JN, Chiu AG, Kennedy DW. Use of intraoperative CT scanning in endoscopic sinus surgery: a preliminary report. Am J Rhinol 2008;22(2):170-4.

40) Conley DB, Tan B, Bendok BR, Batjer HH, Chandra R, Sidle D, et al. 
Comparison of Intraoperative Portable CT Scanners in Skull Base and Endoscopic Sinus Surgery: Single Center Case Series. Skull Base 2011;21(4):261-70.

41) Chennupati SK, Woodworth BA, Palmer JN, Cohen NA, Kennedy DW, Chiu AG. Intraoperative IGS/CT updates for complex endoscopic frontal sinus surgery. ORL J Otorhinolaryngol Relat Spec 2008;70 (4):268-70.

42) Kawamata T, Iseki H, Shibasaki T, Hori T. Endoscopic augmented reality navigation system for endonasal transsphenoidal surgery to treat pituitary tumors: technical note. Neurosurgery 2002;50(6): 1393-7.

43) Lapeer R, Chen MS, Gonzalez G, Linney A, Alusi G. Image-enhanced surgical navigation for endoscopic sinus surgery: evaluating calibration, registration and tracking. Int J Med Robot 2008;4(1):32-45.

44) Dixon BJ, Daly MJ, Chan H, Vescan A, Witterick IJ, Irish JC. Augmented real-time navigation with critical structure proximity alerts for endoscopic skull base surgery. Laryngoscope 2014;124(4): 853-9. 